IZA DP No. 6314

The Effect of Ethnic Identity on the Employment of Immigrants

Nick Drydakis

January 2012 


\title{
The Effect of Ethnic Identity on the Employment of Immigrants
}

\author{
Nick Drydakis \\ University of Patras, \\ Scientific Centre for the Study of Discrimination, Athens \\ and IZA
}
Discussion Paper No. 6314
January 2012

\author{
IZA \\ P.O. Box 7240 \\ 53072 Bonn \\ Germany \\ Phone: $+49-228-3894-0$ \\ Fax: +49-228-3894-180 \\ E-mail: iza@iza.org
}

\begin{abstract}
Any opinions expressed here are those of the author(s) and not those of IZA. Research published in this series may include views on policy, but the institute itself takes no institutional policy positions.

The Institute for the Study of Labor (IZA) in Bonn is a local and virtual international research center and a place of communication between science, politics and business. IZA is an independent nonprofit organization supported by Deutsche Post Foundation. The center is associated with the University of Bonn and offers a stimulating research environment through its international network, workshops and conferences, data service, project support, research visits and doctoral program. IZA engages in (i) original and internationally competitive research in all fields of labor economics, (ii) development of policy concepts, and (iii) dissemination of research results and concepts to the interested public.
\end{abstract}

IZA Discussion Papers often represent preliminary work and are circulated to encourage discussion. Citation of such a paper should account for its provisional character. A revised version may be available directly from the author. 
IZA Discussion Paper No. 6314

January 2012

\begin{abstract}

\section{The Effect of Ethnic Identity on the Employment of Immigrants}

This study evaluates the effect of ethnic identity on the employment level of immigrants in Greece. Treating ethnic identity as a composite of key cultural elements the estimations suggest that employment is positively associated with assimilation and integration and negatively associated with separation and marginalization. In all cases, assimilation provides the highest employment returns, whilst, marginalization provides the highest employment losses. This study adds to the literature by setting up hypotheses, and directly measuring immigrants' ethnic identity commitments. The current results have potentially important implications for post-immigration policies indicating that assimilation and integration policies may be beneficial in terms of labor market outcomes.
\end{abstract}

JEL Classification: F22, J15, J16, Z10

Keywords: ethnic identity, employment

Corresponding author:

Nick Drydakis

Department of Economics

University of Patras

University Campus

26504 Rio

Greece

E-mail:ndrydakis@econ.soc.uoc.gr 


\section{Introduction}

The current study investigates how various forms of immigrant adaptation with respect to the cultures of the origin and Greece affects immigrants' employment. The fact that Greece has always been a migrant-exporting country and has suddenly become a migrant-importing country raised a number of issues that ranged from dealing with racism to the formation of a proper migration policy (Cholezas and Tsakloglou, 2009). Using natives as the gold standard, immigrants have always been compared to natives. In Greece, the scarce economic studies suggest that immigrants face lower wages than natives; are segregated in low status occupations, and are discriminated against in the labor and housing market (Lianos et al, 1996; Demousis et al, 2010; Drydakis and Vlassis, 2010; Drydakis, 2010; Drydakis, 2011a). Unfortunately, however, ethnic identity and employment outcomes have not been subject to examination ${ }^{1}$. Ethnic identity becomes pertinent upon arrival in the host country, given that there is a sufficient cultural distance between the immigrants' country and the receiving country. Nowadays, the multicultural environment in Greece creates many opportunities for international interactions and given the increasing diversity the concept of ethnic identity has become increasingly important ${ }^{2}$. Studies suggest that the choice of

1 Ethnic identity seems most often to be a frame in which individuals identify consciously or unconsciously with those with whom they feel a common bond because of similar traditions, behaviors, values, and beliefs (Ott, 1989).

${ }^{2}$ According to the most relevant census (2001), immigrants from Albania account for more than half of all immigrants $(57.5 \%)$. The second largest group consists of those from Bulgaria (4.6\%), followed by immigrants from Georgia (3.0\%), Romania (2.9\%), and Russia (2.3\%). Recent estimates that take into account undocumented immigrants 
immigrants to be specific types of people may become a powerful decision with substantial socio-economic consequences for both the individuals and the host country. Indeed, Chiswick (1978), Chiswick et al (1997) and Chiswick and Lofstrom (2010) show that as immigrants invest in human capital in the host country, their economic outcomes increase rapidly and can reach and even exceed the economic outcomes of natives.

Given the increasing diversity in Europe today the concept of acculturation has become more and more important. In all multicultural societies, cultural groups and their individual members must deal with the issue of how to acculturate. The classical definition of acculturation was presented by Redfield et al (1936, p. 149): "acculturation comprehends those phenomena which result when groups of individuals having difference cultures come into continuous first-hand contact with subsequent changes in the original culture patterns of either or both group". Ethnic identity becomes salient as part of the acculturation process that takes place when immigrants come to a new society. This study aims to examine associations between ethnic identity patterns and employment levels by utilizing the Greek Migration Study (2009-2010). The Greek Migration Study contains information on various issues surrounding ethnic identity by sampling the five most over-represented immigrant groups in Greece; Albanians, Bulgarians, Georgians, Romanians and Russians. Following the Berry's acculturation model (1980; 1997; 2006) and Constant's and Zimmermann's empirical framework (2008) we construct indexes that measure four possible ethnic identity patterns, namely: integration, assimilation, separation, and marginalization. As Greece is experiencing raise the total number of immigrants in the early years of the twenty-first century to more than one million; i.e. $10 \%$ of the Greek population (Kontis et al, 2006). 
immigration for the first time in historical memory it is critically important to know how immigrants perform in the labor market and affect society. Following the seminal hypothesis of Chiswick (1978) the main question under examination is whether an immigrant who is culturally well adjusted to Greece is likely to face more chances to be in the labor market than an immigrant who retains a stronger affiliation with her or his own culture?

The comparative strength of the current study is immigrants' self-reporting of ethnic identity patterns instead of indirect classifications, which can be experimental and not indicative of true ethnic identity. In the Greek Migration Study, immigrants evaluate the ethnic identity of various key cultural elements by choosing among the four acculturation scenarios to best describe their commitments. The ethnic identity measure adopted is likely to be correlated with the concept of interest, being truly assimilated, integrated, segregated, or marginalized, and is arguably better than the indirect measures used in previous research studies. Measuring ethnic identity by a simple binary variable masks differences in the meaning and use of ethnic identity among immigrants. Migrants may neither look nor feel ethnic or they may affiliate to a greater or lesser degree with the culture of the host country. The study's outcomes will conclude that assimilation and integration provide the highest employment returns. On the other hand, marginalization and separation provides the highest employment losses. The estimated patterns suggest that the formal institutions of the Greek labor market remain the province of the Greek culture characteristics and are more accessible to immigrants with knowledge of the host country language and social capital, regardless of the individual's additional ethnic background. There are a number of reasons why the assimilation of immigrants matters, aside from their employment rates, well-being, savings, 
investments and money transferred to home countries. The more successfully immigrants are employed, the higher their net economic and fiscal contribution to the host economy will be. Whilst, assimilated immigrants may be important for the attitudes of the native population towards immigrants and, therefore, may have an impact on immigration policy. Indeed, Epstein and Gang (2009) and Constant and Zimmermann (2011) suggest that since immigration is the consequence of policy, migration policy is partly responsible for the types of immigrants a country receives, their economic performance, the functioning of the economy, and hence natives' perceptions towards immigrants. Whilst, efforts made to assimilate, time, and the degree to which the majority welcomes the minority are additional elements working to bring minorities into line with the majority. As a result, the current results have potentially important implications for post-immigration policies indicating that assimilation policies may be beneficial in terms of social welfare.

The rest of the study is organized in five sections. A literature review regarding basic concepts of ethnic identity is offered in Section 2, and Section 3 evaluates how the Greek Migration Study classifies ethnic identity. Section 4 presents the descriptive statistics, the formation of identity and the estimation results. Section 5 is a conclusion.

\section{Ethnic identity: Review of the literature}

Identity is a concept widely used in other disciplines but it is relatively new to economics (Davis, 1995; 2003; Akerlof, 1997; Kirman and Teschl, 2004; 2006). Identity is used to describe a person's social category — a person is a man or a woman, a black or a white, a manager or a worker (Akerlof and Kranton, 2005). Identity is also used to describe a person's self-image; it captures how people feel about themselves, as 
well as how those feelings depend upon their actions. Identity corresponds to individuals' own self-classifications and also to their classifications of other people, and suggests a natural way in which behavior can vary within a population (Akerlof and Kranton, 2010; Benabou and Tirole, 2011). These views are related to the developmental theory (Erikson, 1968; 1975; 1985), and social identity theory (Tajfel and Turner, 1979; Tajfel, 1981; Turner, 1982) in social psychology, which provide a conceptual framework for understanding intergroup relations.

In brief, Erikson's psychosocial theory $(1968 ; 1975 ; 1985)$ of development considers the impact of external factors, parents and society on personality development from childhood to adulthood. Erikson demonstrates that personality develops in a series of stages, and in each stage, people experience a conflict that serves as a turning point in development (Erikson, 1975). One of the main elements of Erikson's theory is the development of ego identity. Ego identity is the conscious sense of self that people develop through social interaction. According to Erikson, the ego identity is constantly changing due to new experience and information people acquire in their daily interactions with others (Evans, 1995). Moreover, Tajfel's and Turner's (1979) social identity theory asserts that group membership creates in-group self-categorization and enhancement in ways that favor the in-group at the expense of the out-group. Tajfel and Turner (1979) identify three variables whose contribution to the emergence of in-group favoritism is essential: i) the extent to which individuals identify with an in-group to internalize that group membership as an aspect of their self-concept, ii) the extent to which the prevailing context provides ground for comparison between groups, and iii) the perceived relevance of the comparison group, which itself will be shaped by the relative and absolute status of the in-group. Individuals are likely to display favoritism 
when an in-group is central to their self-definition and a given comparison is meaningful or the outcome is contestable (Hogg and Vaughan, 2002).

The latest theoretical literature in economics has addressed issues of identity. Akerlof (1997) informally discusses the link between preferences and economic outcomes. The author constructs a model where status and conformity are key drivers of individual outcomes including educational attainment, law breaking behavior and childbearing. Akerlof and Kranton (2000) incorporate the concept of identity into a standard individual utility function and present a range of examples where the choice of identity affects individual economic decisions beyond what standard economic theory suggests. The authors argue that individuals earn additional utility from an identity that matches their ideals. A few examples are presented where the choice of identity affects individual interactions and hence economic outcomes. Identity may create externalities for others and provoke reactions that affect individual' own payoffs, as well as, identity may change preferences, with potential consequences for economic outcomes. The authors extend their identity series with studies on identity and schooling, as well as with studies on identity and the economics of organization. Akerlof and Kranton (2002) propose a theory in which a student's primary motivation is his or her identity and the quality of a school depends on how students fit in a school's social setting. Whereas, Akerlof and Kranton (2005) construct models to show how the identities of employees, who may identify with their firms, workgroups or jobs motivations can be included in an economic analysis. More recently, Benabou and Tirole (2011) construct a complementary theoretical framework, which emphasizes the management of beliefs and the cognitive mechanisms leading to identity investments. The authors develop a 
theory of moral behavior, individual and collective, based on a general model of identity in which people care about who they are and infer their own values from past choices.

Examples of identities include ethnic identity patterns. The idea of ethnic identity has developed to refer to an individual's sense of self in terms of membership in a particular ethnic group and contemporarily is generally seen as embracing various aspects, including self-identification, feelings of belongingness and commitment to a group, a sense of shared values, and attitudes toward one's own ethnic group (Berry, 1980; 1997; 2006; Liebkind, 1992, Phinney et al 2001). Ethnic identity forms and becomes a strong part of the immigrant's persona when they arrive in a host country that is dominated by a different ethnicity, culture, and language. As Constant and Zimmermann (2008) point out, ethnic identity is like a property that a person can have for some time, can lose and acquire a new, or can lose and never assume another one. Ethnic identity makes it possible to compare migrants within an ethnic group and to draw parallels between representatives of different ethnicities. Immigrants arrive in a new country with differing attitudes about retaining their cultures of origin and becoming part of the new society. In the new society, however, these attitudes interact with the actual and perceived levels of acceptance of immigrants and with official policies toward immigration (Phinney et al, 2001). Ethnic identity is likely to be strong when immigrants have a strong desire to retain their identities, when pluralism is encouraged or when immigrant groups feel accepted. However, some immigrants may downplay or reject their own ethnic identities in the face of real or perceived hostility toward them or toward particular groups. Other immigrant groups may assert pride in their cultural group and emphasise solidarity as a way of dealing with negative attitudes. In general, as Akerlof and Kranton (2000) and Ihlanfeldt and Scafidi (2002) suggest the 
relationship will be influenced by the interaction of the characteristics of specific groups with those of particular setting.

Few theoretical economic studies examine how ethnic traits are transmitted either from parents to children, or through religious intermarriage, and how ethnic identity is adopted (Bisin and Verdier, 2000; 2001, Bisin, et al 2004). Parents directly make various socialization choices, e.g. the rules and beliefs the family conforms to and how much time they spend with their children. Whilst, minority groups search more intensely for intergroup mates and spend more resources to socialize their offspring. Moreover, the widely discussed peer effect entitled 'acting white' (i.e. some minority adolescents ridicule their minority peers for engaging in behaviors perceived to be characteristic of whites) is also formalized. Austen-Smith and Fryer (2005) show that without peer effects, equilibria involve all ability types choosing different levels of education. 'Acting white', however, alters the equilibrium dramatically. The set of lowest ability individuals and the set of highest ability individuals continue to reveal their type through investments in education, while, ability types in the middle interval pool on a common education level. In addition, Bisin et al (2011a) develop a dynamic model of identity formation that explains why ethnic minorities may choose to adopt oppositional identities (i.e. some individuals may reject or not the dominant culture) and why this behavior may persist over time. The authors evaluate that an oppositional culture in the minority group can be sustained in steady state if there is enough cultural segmentation in terms of role models, or if the size of the minority group is large enough, or if the degree of oppositional identity is high enough. It is evaluated also that the higher the level of harassment and the number of racist individuals in the society, the more likely an oppositional minority culture will emerge. Furthermore, scarce 
theoretical models investigate how ethnic identity associates with economic outcomes. For instance, Battu et al (2007) examine the relationship between oppositional identities among ethnic groups and employment. The authors develop a model in which nonwhite individuals are defined with respect to their social environment (family, friends, neighbors) and their attachments to their culture of origin (religion, language). The authors evaluate that contingent on the strength of peer pressures, nonwhites choose to adopt oppositional identities because some individuals may identify with the dominant culture and others may reject that culture even if it implies unfavorable labor market outcomes.

Although there are differences depending on how one measures ethnic identity and each country does have a very different immigration policy some recent studies highlight interesting patterns. Mason (2004), using US data from the 1979 Chicano National Survey; the 1990 Latino National Political Survey; and the 1990 Latino National Political Survey/Panel Study on Income Dynamics Early Release File, estimates strong incentives favoring acculturation among Mexican- and CubanAmericans. Americans of Mexican and Cuban descent but less so Puerto Ricans are able to increase annual income and hourly wages by acculturating into a non-Hispanic white racial identity. However, neither the abandonment of Spanish nor the abandonment of a specifically Hispanic racial self-identification is sufficient to overcome the penalties associated with having a dark complexion and non-European phenotype. Social identity measurement was constructed by considering Spanish fluency, own-color identity (from very light to very dark) and phenotype (from European looking to Indian looking). Pendakur and Pendakur (2005), using the Canadian Equality, Security and Community Survey, for the period 2000 and 2002, 
examine the effects of ethnic identity on the use of informal networks to obtain jobs and on employment itself. It is estimated that for European ethnic minorities the strength of minority identity is positively related to the use of informal methods for gaining employment but there is no effect for non-European and non-Aboriginal origin. Ethnic identity was measured by the relevant question: "is your ethnic origin very important to you, somewhat important, not very important or not at all important".

In UK, Battu and Zenou (2010), using the Fourth National Survey of Ethnic Minorities collected in 1993/4, suggest that social environment of individuals and attachments to culture of origin have a strong association with identity choice. In particular, the authors suggest that those non-whites who have preferences that accord with being oppositional do experience an employment penalty. Five dichotomous dependent variables were constructed to measure oppositional identities. For instance, an individual had to answer: "if strongly disagrees that in many ways he or she thinks himself/herself as British”. Casey and Dustmann (2010), using data from 22 waves of the German Socio-Economic panel (initiated in 1984) do not find evidence of a strong positive association between labor market outcomes of male foreign born individuals and the German identity. They do find some association between a German identity and favorable labor market outcomes for females. Interestingly, for the second generation, the authors find no significant association between either identity measure and female labor market outcomes. For males, the evidence points at a positive association between home country identity and labor market outcomes. Individuals and their children were asked on a five-point scale about how strongly German they feel and how strongly they feel connected to their origin country. In addition, Aldashev et al (2009), using the German Socio-Economic panel for the years 1996 to 2005, show that language 
proficiency may not only affect the earnings of the individual, but the probability to participate in the labor market or becoming employed as well. Two dependent variables were constructed. The first variable measured language usage in the household (from mainly German to mainly mother tongue). The second variable measured self-assessed language proficiency (from very good to not at all).

Constant et al (2007), Constant and Zimmermann (2008) and Constant et al (2009a; 2009b; 2009c), using the German Socio-Economic panel for the years 2000 to 2002, provide positive associations between commitment to the host country and work participation, earnings and housing decisions. Ethnic identity measurements were constructed by identifying in the German Socio-Economic panel survey pairs of questions with respect to language, visible cultural elements, ethnic self identification and future citizenship plans (ranging from very good to bad). Nekby and Rodin (2010), using the Follow-up Surveys of Pupils from Statistics Sweden for the year 1995, indicate no significant differences in employment probabilities between those that identify only with majority and those that identify with both the majority culture and the ethnic group. What appears to matter for employment outcomes is an attachment to the majority culture while a strong attachment to the ethnic group is not per se detrimental for employment outcomes. Two questions were asked in the following order: to what degree do you feel affinity to your original background culture? To what degree do you feel affinity to Swedish culture? Answers to these questions were coded into a fourlevel scale based on the answer options available (completely, partially, little, not at all). Constant et al (2007), Constant and Zimmermann (2008); Constant et al (2009a; 2009b; 2009c) and Nekby and Rodin (2010), based on Berry's (1980; 2006) theory of 
acculturation, classified individuals as assimilated, integrated, separated and marginalized.

Finally, Bisin et al (2011b) study the relationship between ethnic identity and labor market outcomes of non-EU immigrants in Europe. Using the European Social Survey (EU-funded survey conducted in most European countries every two years, starting from 2002) the authors find that being a first generation immigrant leads to a penalty while second generation immigrants have a probability of being employed that is not statistically different from that of natives. However, when they have a strong identity, second-generation immigrants have a lower chance of finding a job than natives. Questions about the 'attachment to religion', the 'importance of following traditions and customs', and the 'language most often spoken at home' were employed to measure ethnic identity. Unfortunately, however, information on the relationship between ethnic identity and the identity of the 'majority' group where this person lives did not contain. Conclusively, all these empirical studies imply that there is a strong identification with the majority culture that is important in order to succeed on the labor market and that the degree of identification with the cultural background seems to be less important.

\section{Study's framework}

In the current study, Berry's $(1980 ; 1997 ; 2006)$ framework of acculturation, and the associations between ethnic identity and labor market outcomes as described in the Section 2, give us incentives to demonstrate four hypotheses, valuable for the scope of this study. Setting up and testing hypotheses is essential for the systematic study of ethnic identity and labor market outcomes. The acculturation framework developed in 
the cross-country psychology literature allows individuals to self-identify or be categorized into acculturation states reflecting strength of affiliation to both the ethnic group and the majority society. According to Berry $(1980 ; 1997 ; 2006)$ an immigrant who abandons his/her own cultural habits and values, in order to accept the new country totally has an assimilated identity, whereas, an immigrant who holds on to some aspects of his/her own culture and values, and at the same time, tries to melt in to the new cultural environment is considered to have an integrated identity. An immigrant who focuses on keeping his/her own values and avoid contact with the majority culture as much as he/she can have a separated identity. Finally, an immigrant who does not keep hold on to his/her original culture, nor integrates in the new culture has a marginalised identity. Berry's model presents abroad theoretical view of possible identity categories that may be evident among immigrants.

An important question, then, is why ethnic identities should have any impact on economic outcomes. Scholar studies suggest that with time spent in the host country, immigrants become more like natives because they are exposed to the new culture and are investing in local social capital. As a result the acquisition of host country language and cultural understanding provides access to information, social networks, and the human capital required to succeed in the host country (Chiswick, 1978; Borjas, 1985; Borjas et al, 1992; Chiswick et al, 1997; Berry, 1997; 2006; Izquierdo et al, 2009; Beenstock et al, 2010; Chiswick and Lofstrom, 2010). However, studies show also that maintaining a commitment to the culture of origin after immigration can be beneficial because it provides immigrants with valuable ethnic-specific capital. Immigrants may have greater employment advantages in the labor market, due to knowledge of two languages, possession of ethnic capital, and access to two ethnic networks (Borjas et al, 
1992; Berry, 2006; Constant and Zimmermann, 2008; 2011; Constant et al, 2009a; $2009 b ; 2009 c)$. On the other hand, a few studies suggest that isolation from the host country's culture may lead immigrants not to investment in specific human and social capital required in the host labor market (Akerlof and Kranton, 2000; Selod and Zenou, 2006; Constant and Zimmermann, 2008; Battu and Zenou; 2010). Whilst, immigrants distancing from their origin country's human and social capital, as well as, distancing from host country's social networks and investments in human capital may entail much reduced social support and hostility (Berry and Sam, 1997; Battu and Zenou, 2010). Actually, empirical findings suggest that immigrants who have preferences that accord with being oppositional do experience extensive employment penalties (Battu and Zenou, 2010; Nekby and Rodin, 2010).

Thus, four hypotheses related to ethnic identity and immigrants' employment are developed: On the one hand, assimilation is likely to provide positive employment returns to immigrants, due to adoption of the host country language, and cultural habits. Integration, however, is likely to provide even greater employment returns to immigrants, compared to assimilation, as the access to two distinct cultural networks further rises employment opportunities in the host labor market. On the other hand, as long as, separation entails inadequate human and social capital in the host country may not be beneficial for employment. Meanwhile, marginalisation is likely to result in even higher employment losses, compared to separation in the host country due to immigrants' isolation from two distinct cultural networks. As a result, the ways that immigrants adapt to differences between the cultures of the original and host countries 
are of great interest, as is the related question of how ethnic identities affect immigrants' employment status and economic welfare ${ }^{3}$.

In order to evaluate the study's hypothesis the Greek Migration Study identified direct questions regarding immigrants' personal devotion to the host culture and society with the commitment to the culture and people of their origin by combining information on language, cultural habits (food, media, music and reading), self-identification, societal interaction, and future citizenship plans ${ }^{4}$. Table 1 presents the relevant questions and the options. Immigrants had to evaluate the ethnic identity patterns of the five cultural elements by choosing among the four alternative scenarios to best describe their commitments. The four scale scores were calculated by summing the responses within each category. Taking into account the five critical questions the assimilation variable could equal to $x$ if the options that correspond to assimilation were chosen $x$ times. The same holds for integration, separation and marginalisation (see also, Constant and Zimmermann, 2008). It is clear that these scales give equal weight to each of the five aspects of ethnic identity, including the direct measure of ethnic self-

\footnotetext{
${ }^{3}$ Keep in mind that, as Sayegh and Lasry (1993) and Schwartz and Zamboanga (2008) evaluate not all of Berry's (1980) categories may exist in a given sample, and that some categories may have multiple subtypes.

4 The cultural elements most frequently employed in ethnic identity studies are language, media, food preferences, and societal interaction (Phinney,1992; Nguyen and von Eye, 2002; Unger et al, 2002; Laroche et al, 2005; Constant and Zimmermann, 2008; Bisin et al, 2011b).
} 
identification, and allows for potential differences in four dimensions rather than just self-evaluation alone (see, Berry, 1980; 1997; 2006; Constant and Zimmermann, 2008).

(Table 1)

The added value of this study is significant when compared to the studies mentioned in the literature review section. The current methodology adds to the literature by establishing hypotheses and empirically examining ethnic identity and employment by using the more flexible categorisation of identity that the acculturation framework provides. More importantly, the comparative strength of this study is that immigrants evaluate the ethnic identity commitments of the key cultural elements by choosing among direct acculturation scenarios to best describe their ethnic identities, instead of indirect classifications, which can be experimental and not indicative of true ethnic identity. For instance, as we discussed in Section 2, the previous studies classified immigrants as assimilated if they claimed to feel very native. However, these migrants may have also been integrated. In fact, in previous studies, immigrants who claimed that a host country's culture was very important to them did not have the option to choose whether their home country's culture was important to them. It may have been important to a lower, higher or even the same degree. Similarly, previous studies coded immigrants as separated if they claimed to have limited ability to communicate in the native language. However, these immigrants may have also been marginalised. Thus, the previous literature did not allow immigrants to (firmly) self-identify their acculturation status. However, in the current study, the direct measure of ethnic identity is likely to be correlated with the concept of interest (i.e., being truly assimilated, integrated, segregated, or marginalised), and is arguably better than the indirect measures used previously. In the current study, immigrants were able to read, evaluate 
and decide which acculturation condition best described their ethnic identity patterns. Therefore, our measurement may be of further interest to economists and social scientists, and may serve as a framework for integrating the existing body of evidence, as well as for structuring future research efforts.

\section{Outcomes' Presentation and Discussion}

4a. Descriptive statistics

The 2009-2010 Greek Migration Study consisted of written surveys in the six largest cities in Greece; Athens, Thessaloniki, Patra, Iraklion, Larisa and Volos, in which immigrants are most heavily concentrated (Census, 2001). The data gathering was conducted from February 2009 to July 2010 by the University of Piraeus, the University of Central Greece, and Panteion University of Social and Political Sciences, on large pools of immigrants; immigrants' centres and institutions, governmental and non-governmental organisations that deal with immigrants, and antiracism centres. The data-gathering process generated samples of a typical validated size of 1,837 immigrants. The sample was restricted to individuals aged $18-65$, whose nationality is not Greek, who were not born in Greece, and who were not in school at the time of the survey (see also, Constant and Zimmermann, 2008; Casey and Dustmann, 2010; Manning and Roy, 2010).

Table 3, shows the descriptive statistics, and for convenience the variable definitions are summarised in the Table 2. As it is observed, the largest portion of the immigrants is classified as separated (1.9), followed by those measured to be integrated (1.4), assimilated (1.1) and marginalised (0.5). Immigrants identify most with the culture of the home country. The same pattern is observed by Constant and Zimmerman 
(2008). As regards the basic demographic variables, the sample consists of $36.1 \%$ Albanians, $12.5 \%$ Bulgarians, $12.2 \%$ Georgians, $18.6 \%$ Romanians, and $20.4 \%$ Russians. The labor force consists of $85.3 \%$ employed and $14.6 \%$ unemployed. The majority of employed are men (59.8\%), whereas the majority of unemployed are women (62.1\%). Immigrants' average age is 36.9 , they have 15.4 years of time living immigrated in Greece, and they have 14.4 years of actual work experiences in Greece. As regards education levels, $17.2 \%$ have a university or technical school degree; $64.4 \%$ have a high school diploma; and $75.5 \%$ of the immigrants have completed the minimum mandatory education. Importantly, a comparison between the 2009-2010 Greek Migration Study data set and the 2005 Greek Household Budget Survey reveals similar average ages of the respondents, gender division of immigrants and employment rates which suggests that the Greek Migration Study survey is, to a large extent, representative of immigrants in Greece.

(Table 2)-(Table 3)

\section{4b. The formation of identity}

Before examining how the various patterns of ethnic identity are associated with employment rates, one should also consider the determinants of identity for immigrants because there is no existing evidence on the ethnic identity of immigrants in Greece. As reported by Constants et al (2009a), Manning and Roy (2010), and Casey and Dustmann (2010), Table 4 presents the results from regression of Greek and home country identities on the various personal characteristics discussed in the descriptive statistics section. The estimation framework consists of robust Poisson regressions using a larger number of pre- and post-migration characteristics as determinants (Constants et al, 
2009a). The estimations suggest that young immigrants are the best assimilated and integrated. Moreover, men are assimilated to a greater degree than are women. Spending more years in Greece has a positive impact on assimilation and integration. Furthermore, Christians are more integrated and less marginalised. Health impairments have a positive effect on separation. Minimum mandatory education in the home country is harmful for the process of integration. However, immigrants with university or technical school diplomas in the home country tend to assimilate and integrate and are less separated. Knowledge of the English language proved to have a positive effect on assimilation and integration. As for the labor market determinants, those in the labor force are more likely to be assimilated and integrated and less likely to be separated and marginalised, whereas those being employed are more likely to be assimilated and less likely to be separated. With regards to immigrant groups, Bulgarians are more likely to be separated. Georgians are less likely to be integrated and more likely to be separated. Romanians are less likely to be integrated and more likely to be marginalised. Russians are more likely to be integrated and less likely be separated. These results share common ground with those of recent studies. Manning and Roy (2010) suggest that newly arrived immigrants almost never think of themselves as British, but the longer they remain in the United Kingdom the more likely it is that they will do so. In addition, Casey and Dustmann (2010) estimate that years since migration and years of education are positively associated with a stronger German identity and negatively associated with ethnic minority identity. Furthermore, Constant et al (2009a) found results comparable to this study and indicate that a successful immigration policy aiming at decent integration and assimilation has to rely largely on entry selection. Attachment to the 
labor markets and to the cultures of the receiving countries seem to be essential for economic success.

(Table 4)

\section{4c.Outcomes' analysis}

The employment regression results (marginal effects) are found in Table 5. As in Constant and Zimmermann (2008), Battu and Zenou (2010), Casey and Dustmann (2010), Bissin et al (2011b) the employment equation, relates the employment levels to dummy variables for the independent variables. The variables of interest are those which indicate ethnic identity. As it is observed, assimilation is positively associated with employment rates by around $6.9 \%$. Similarly, integration is positively associated with employment rates by around 5.1\%. Obviously, assimilation provides higher employment returns to immigrants than integration. On the other hand, separation is negatively associated with immigrant employment rates by around $12.6 \%$, and marginalization is also negatively associated with immigrant employment rates by around $14.2 \%$. We conclude that marginalization is associated with higher employment losses than separation. The current estimations suggest that it is host country commitment, rather than attachment to the country of origin that determines higher employment rates ${ }^{5}$

Similarly, Battu and Zenou (2010) show that non-whites who strongly disagree with the notion of being British are less likely to be employed by around 7\%. Moreover,

\footnotetext{
${ }^{5}$ In Table 5, the other control variables of interest have expected coefficients. Age, being male, married, number of children, years since immigration, work experience and each education variable all have positive effects on employment rates.
} 
Constant et al (2007), Constant and Zimmermann (2008), Constant and Zimmermann (2009c), Casey and Dustmann (2010), and Nekby and Rodin (2010) find evidence of a positive association between employment rates and the host country identity. Whilst, the current Greek patterns become more robust when we consider an additional Greek study (Drydakis, 2011b) that shows that assimilation and integration are positively associated with immigrant wages, while separation and marginalisation are negatively associated with immigrant wages. Hence, there is evidence that assimilation and integration entail employment and wage advantages. Importantly, we have to highlight, however, that the current outcomes are relations and should not be evaluated in a causal way. Following Casey's and Dustmann's (2010) suggestion we may interpret the study's estimates as an upper bound of any effect of identity on employment outcomes. In addition, needless to say that the current estimates are strictly applicable only to the time, place, immigrant groups, individual demographic, and social and labor characteristics from which the sample was drawn.

For more information, in Table 6, we perform separate regressions for each ethnic group; Albanians, Bulgarians, Georgians, Romanians and Russians. It is estimated that immigrants who have greater identification with Greek culture and society have higher employment levels, whilst separated and marginalised immigrants face employment disadvantage. Although we estimate a steady pattern for all ethnic groups we should highlight that identities and their role in adaptation can best be understood in terms of an interaction between the attitudes and characteristics of each immigrant group and the responses of the receiving society, moderated by the particular circumstances of the ethnic group within the new society. Studies suggest that a more nuanced approach, based on Berry's (1980) acculturation framework but adjusting for 
the many variations among immigrants and among their social conditions, may have more explanatory power and applicability (Chirkov, 2009).

(Table 5) - (Table 6)

To continue with, in Table 7, we conduct simulations on employment rates and we estimate the variations in immigrant employment rates in the cases of full assimilation, integration, separation and marginalization (see, Constant and Zimmermann, 2008). On average, there is an advantage of assimilation above integration, and there is a greater disadvantage of marginalization in comparison with separation. As it can be observed if immigrants were fully assimilated, their employment would grow by $16.9 \%$. If immigrants were fully integrated, their employment would grow by $8.2 \%$. On the other hand, a full separation would lead to an $11.9 \%$ reduction in employment rate. A full marginalisation would decrease the employment by $23.5 \%$. Constant and Zimmermann (2008) found comparable outcomes. In Table 7, we also offer simulations for each ethnic group. Similar patterns are estimated. The estimations suggest that there is a strong identification with the majority culture that is important in order to succeed on the labor market and that the degree of identification with the cultural background seems to be less important.

\section{(Table 7)}

Thus, in the current study we conclude that immigrants who accept the new country's cultural elements are more likely to be employed. Chiswick (1978) and Chiswick and Lofstrom (2010) suggest that as immigrants gain information access about the functioning of the new environment and invest in human and social capital in the host culture, their labor market outcomes increase rapidly. The knowledge of the host language and the acquisition of basic skills are important for immigrants, as 
without them, many immigrants find it difficult to enter the labor market, and as a result many of them remain at the margins of society long after they have moved into the receiving country (Borjas, 1985; Berry and Sam, 1997; Chiswick et al, 1997; Battu and Zenou, 2010; Casey and Dustmann, 2010). We should highlight that integrated immigrants do not face a higher advantage in the Greek labor market. Berry and Kalin (1995) suggest that the integration strategy can only be pursued in societies that are explicitly multicultural, in which pre-conditions are established. These pre-conditions are: the widespread acceptance of a positive multicultural ideology; relatively low levels of prejudice and discrimination, no specific intergroup hatreds; and a sense of attachment to, or identification with, the larger society by all groups. In Greece, Drydakis (2010, 2011a) and Drydakis and Vlassis (2010) found patterns of ethnic segregation and extensive discrimination in the labor and housing market that might jeopardise immigrants' integration. When the media occasionally bring to light conflicts between immigrants and Greeks, immigrants complain that they face prejudice, and nationals complain that quiet places turn into ghettos. As Lyberaki and Pelagidis (2000) suggest the challenges raised by immigration have crystallized into several forms, including concerns about immigrants posing a threat to natives and their jobs as well as immigrants as a menace to the Greek welfare state. The European Union Agency for Fundamental Rights (2007) suggests that each wave of migrant newcomers in the Greece is believed to be a major source of crime, improvidence and other forms of socially undesirable conduct. As long as ethnic identity is associated with the social environment and the respective expected behaviour, deviations from the prescription generate disutility (Battu and Zenou, 2010). Note also that the feeling of not belonging to the majority group may lead immigrants not to participate in social activities of 
majority individuals that help to develop network structures supportive of economic success (Casey and Dustmann, 2010). Poor economic success may lead then to social and economic exclusion of immigrants, which in turn may lead to social unrest (Alesina and La Ferrara, 2002).

Algan et al (2010) and Chiswick and Lofstrom (2010) propose, the more successful immigrants are in labor market, the higher their net economic and fiscal contribution to the host economy will be. Immigrant success influences the "fiscal balance" of immigration, whether immigrants pay more in taxes than they receive in benefits from the government in the destination. There is evidence that governments are moving in this direction and against the policy of multiculturalism that, according to its critics, has actively discouraged assimilation by excessive celebration of diversity (Sen, 2006). Trevos Phillips (2005), the chairman of the European Commission for Racial Equality, argued in his speech ('Sleepwalking to Segregation') at the Manchester Council for Community Relations that multiculturalism was leading to segregation. The attention paid to ethnic identity, and the adverse consequence of multiculturalism is novel in Greece and does represent a departure from the long-standing debate which has tended to emphasize ethnic discrimination as the key source of immigrants' disadvantages. Day by day, an intense political and intellectual debate is taking place in Greece around migration issues, ethnic identity, and immigrants' human capital. Indeed, in 2010 Greece approved an examination that requires knowledge in written Greek, Greek history, and Greek political values for legal immigrants who have been in the host country for five years and are seeking Greek citizenship (Ministry of Interior 2010/3833). Scholar studies acknowledge the three elements required to bring minorities into line with the majority: assimilation efforts, time and the degree to which 
the majority welcomes the minority (Epstein and Gang, 2009). The choice of immigration policy affects the growth and performance of an economy, the characteristics of the immigrant groups a country receives, as well as the perception of immigrants by the natives ${ }^{6}$. A general presumption is that immigrants who are selected according to their knowledge and skills are more likely to be successful in the host country, and to assimilate relatively more rapidly, as compared to chain migrants or refugees, into the new economic environment. Thus, an immigration policy is designed to give preference to certain groups and immigrants' characteristics (Bauer et al, 2000). In the current study, we contribute to such a debate by providing Greek evidence on the relationship between ethnic identity and immigrants' employment levels. Greece needs an economically motivated migration policy, which does not ignore the need to deal with ethnic identity, especially assimilation and integration. The current study suggests that assimilated immigrants have better employment potentials. Similarly, the US, Canadian, UK, Spanish and German studies reviewed in this paper suggest that there should be a strong identification with the majority culture in order to succeed on the labor market.

\footnotetext{
${ }^{6}$ As Bauer et al (2000) suggest if humanitarian criteria are used in determining entry into the country success in the labor market may be harder to come by for these immigrants, since their skills may be less transferable; thus assimilation may be less likely to take place and the costs of integrating these migrants into the society and the labor market might be high.
} 


\section{Conclusions}

The current study adds to the literature by setting up hypotheses and empirically examines ethnic identity and employment levels using the more flexible categorization of identity provided by the acculturation framework (Berry, 1980; 1997; 2006). The comparative strength of this study is that immigrants in the 2009-2010 Greek Migration Study self-evaluate their ethnic identity patterns by choosing among direct acculturation patterns of key cultural elements. Hence, the adopted measure is likely to be correlated with the concept of interest, being truly assimilated, integrated, segregated, or marginalized, and is arguably better than the indirect measures used in previous research. The current results have potentially important implications for postimmigration policies indicating that assimilation and integration policies may be beneficial in terms of immigrants' employment levels. The study concludes that Albanian, Bulgarian, Romanian, Georgian, and Russian immigrants who are culturally well adjusted in Greece are more likely to be employed than immigrants who remain strongly attached to their own culture. Meanwhile, the results indicate employment growth for fully assimilated and integrated immigrants and employment losses for totally separated and marginalised immigrants. Notably, in all cases, assimilation is estimated to provide the highest employment returns to immigrants, while, marginalization entailed the highest employment losses. A healthy Greek, as well as, a European immigration system should recognise labor immigration flows and the potential of repeat immigration and evaluate the cornerstone features of ethnic identity. If a policy stressing labor market demands is implemented, it is also quite likely that the immigrants will perform relatively well in the labor market and contribute to the growth and the performance of the economy. Steadily, the limited European research is 
showing that assimilation and integration result in positive economic outcomes, but information from the constituent member states is valuable for a complete picture so that policy changes can take place. 


\section{References}

Akerlof, G. A. (1997). Social Distance and Social Decisions. Econometrica, 65:10051027.

Akerlof, G. A. Kranton, R. E. (2000). Economics and Identity. Quarterly Journal of Economics, 115:715-753.

Akerlof G. A, Kranton, R. E. (2002). Identity and Schooling: Some Lessons for the Economics of Education. Journal of Economic Literature, 40:1167-120.

Akerlof G. A, Kranton, R. E. (2005). Identity and the Economics of Organizations, Journal of Economic Perspectives, 19: 9-32.

Akerlof, G. A. Kranton, R. E. (2010). Identity Economics: How Our Identities Shape Our Work, Wages, and Well-Being. Princeton University Press, Princeton.

Aldashev, A. Gernandt, J and Thomsen, S. (2009). Language Usage. Participation, Employment and Earnings. Evidence for Foreigners in West Germany with Multiple Sources of Selection. Labour Economics, 16:330-341.

Alesina, A. and La Ferrara, E. (2002). Who Trusts Others? Journal of Public Economics ,85:207-234.

Algan, Y. Dustmann, C. Glitz, A. and Manning, A. (2010). The Economic Situation of First and Second-Generation Immigrants in France, Germany and the United Kingdom. The Economic Journal, 120:4-30.

Austern-Smith D. and Fryer, Jr. R. D. (2005). An Economic Analysis of 'Acting White. Quarterly Journal of Economics, 120:551-583.

Battu, H. McDonald, M. and Zenou, Y. (2007). Oppositional Identities and the Labour Market. Journal of Population Economics, 20:643-667. 
Battu, H. and M. Zenou, V. (2010). Oppositional Identities and Employment for Ethnic Minorities: Evidence from England. The Economic Journal, 120:52-71.

Bauer, K. T. Lofstrom, M. and Zimmermann, K. F. (2000). Immigration Policy, Assimilation of Immigrants and Natives' Sentiments towards Immigrants: Evidence from 12 OECD-Countries. Swedish Economic Policy Review, 7:11-53.

Beenstock, M. Chiswick, B. R. and Paltiel, A. (2010). Testing the Immigrant Assimilation Hypothesis with Longitudinal Data. Review of the Economics of the Household, 8:7-27.

Benabou, R. and Tirole, J. (2011). Identity, Morals, and Taboos: Beliefs as Assets. Quarterly Journal of Economics, 126:805-855.

Berry, J. W. (1980). Acculturation as Varieties of Adaptation, in Padilla, A. M. (Ed.). Acculturation: Theory, Models and Some New Findings (9-25). Westview, Boulder.

Berry, J. W. and Kalin, R. (1995). Multicultural and Ethnic Attitudes in Canada. Canadian Journal of Behavioural Science, 27:301-320.

Berry, J. W. and Sam, D. (1997). Acculturation and Adaptation, in Berry, J. W. Segall, M. H. and Kagitcibasi, C. (Eds). Handbook of Cross-Cultural Psychology, Vol. 3 (291-326). Allyn and Bacon, Boston.

Berry, J. W. (2006). Contexts of Acculturation, In Sam, D. L. and Berry, J. W. (Eds.). Cambridge

Handbook of Acculturation Psychology (27-42). Cambridge University Press, Cambridge. 
Bisin, A. and Verdier, T. (2000). Beyond the Melting Pot: Cultural Transmission, Marriage, and the Evolution of Ethnic and Religious Traits. Quarterly Journal of Economics, 115:955-988.

Bisin, A. and Verdier, T. (2001). The Economics of Cultural Transmission and the Dynamics of Preferences. Journal of Economic Theory, 97:298-319.

Bisin, A. Topa, G. and Verdier, T. (2004). Religious Intermarriage and Socialization in the United States. Journal of Political Economy, 112:615-664.

Bisin, A. Patacchini, E. Verdier, T. and Zenou, Y. (2011a). Formation and Persistence of Oppositional Identities. European Economic Review, doi:10.1016/j.euroecorev.2011.04.009.

Bisin, A. Patacchini, E. Verdier, T. and Zenou, Y. (2011b). Ethnic Identity and Labour Market Outcomes of Immigrants in Europe. Economic Policy, 26:57-92.

Borjas, G. (1985). Assimilation, Changes in Cohort Quality and the Earnings of Immigrants. Journal of Labor Economics, 3:463-489.

Borjas, G. Bronars, S. Trejo, S. (1992). Assimilation and the Earnings of Young Internal Migrants. The Review of Economics and Statistics, 74:170-175.

Casey, T. and Dustmann, C. (2010). Immigrants' Identity, Economic Outcomes and the Transmission of Identity Across Generations. The Economic Journal, 120:31-51.

Chirkov, V. (2009). Summary of the Criticisms and of the Potential Ways to Improve Acculturation Psychology. International Journal of Intercultural Relations, 33:177-180.

Chiswick, B. R. (1978). The Effect of Americanization on the Earnings of Foreign-Born Men. Journal of Political Economy, 86:897-921. 
Chiswick, B. R., Cohen, Y. and Zach, T. (1997). The Labour Market Status of Immigrants Effects of the Unemployment Rate at Arrival and Duration of Residents. Industrial and Labour Relations Review, 50:289-303.

Chiswick, B. R. and Lofstrom, M. (2010). The Labor Market Adjustment of Immigrants. Review of the Economics of the Household, 8:1-5.

Constant, A. F. Gataullina, L. and Zimmermann, K. F. (2007). Gender, Ethnic Identity and Work. IZA, DP-2420.

Constant, A. F. and Zimmermann, K. F. (2008). Measuring Ethnic Identity and Its Impact on Economic Behavior. Journal of the European Economic Association, 6:424-433.

Constant, A. F. Gataullina, L. and Zimmermann, K. F. (2009a). Ethnosizing Immigrants. Journal of Economic Behavior and Organization, 69:274-287.

Constant, A. F. Rowan, R. and Zimmermann, K. F. (2009b). Ethnic Identity and Immigrant Homeownership. Urban Studies, 46: 1879-1898.

Constant, A. F. and Zimmermann, K. F. (2009c). Work and Money: Payoffs by Ethnic Identity and Gender. Research in Labor Economics, 29:3 - 30.

Constant, A. and Zimmermann, K. F. (2011). Migration, Ethnicity and Economic Integration, in Jovanovic, M. N. (Eds.), International Handbook of Economic Integration (145-168). Edward Elgar Publishing, Cheltenham.

Cholezas, I. and Tsakloglou, P. (2009). The Economic Impact of Immigration in Greece: Taking Stock of the Existing Evidence. Southern European and Black Sea Studies, 9:77-104.

Davis, J. B. (1995). Personal Identity and Standard Economic Theory. Journal of Economic Methodology, 2:35-52. 
Davis, J. B. (2003). The Theory of the Individual in Economics: Identity and Values. Routledge, London.

Demoussis, M. Giannakopoulos, N. and Zografakis, S. (2010). Native-Immigrant Wage Differentials and Occupational Segregation in the Greek Labour Market. Applied Economics, 42:1015-1027.

Drydakis N. (2010). Ethnic Differences in Housing Opportunities. Urban Studies, 47: 2573-2596.

Drydakis N. and Vlassis, M. (2010). Ethnic Discrimination in the Greek Labour Market: Occupational Access, Insurance Coverage, and Wage Offers. Manchester School, 78:201-218.

Drydakis N. (2011a). Ethnic Discrimination in the Greek Housing Market. Journal of Population Economics, 24:1235-1255.

Drydakis, N. (2011b). Ethnic Identity and Immigrants' Wages in Greece. International Journal of Intercultural Relations, DOI:10.1016/j.ijintrel.2011.09.002.

Epstein, G. S. and Gang, N. I. (2009). Ethnicity, Assimilation and Harassment in the Labor Market. Research in Labor Economics, 29: 67-88.

Erikson, E. H. (1968). Identity: Youth and Crisis. Norton, New York.

Erikson, E. H. (1975). Life History and the Historical Moment. Norton, New York.

Erikson, E. H. (1985). Childhood and Society. Norton, New York.

European Union Agency for Fundamental Rights. (2007). Annual Report 2007: Report on Racism and Xenophobia in the Member States of the EU. Luxembourg: EUAFR.

Evans, R. I. (1995). Dialogue with Erik Erikson. Jason Aronson, New Jersey.

Hogg, M. A. and Vaughan, G. M. (2002). Social Psychology. Prentice Hall, London. 
Ihlanfeldt, K. R. and Scafidi, B. (2002). Black Self-Segregation as a Cause of Housing Segregation. Evidence from the Multi-City Study of Urban Inequality. Journal of Urban Economics, 51:366-390.

Izquierdo, M. Lacuesta, A. and Vegas, R. (2009). Assimilation of Immigrants in Spain: A Longitudinal Analysis. Labour Economics, 16:669-678.

Kirman, A. Teschl, M. (2004). On the Emergence of Economic Identity. Revue de Philosophie Economique, 9:59-86.

Kirman, A. Teschl, M. (2006). Searching for Identity in the Capability Space. Journal of Economic Methodology, 13:299-325.

Kontis, A. Zografakis, S. and Mitrakos, Th. (2006). The Economic Impact of Employing Immigrants During the Last Decade in GDP. Hellenic Migration Policy Institute, Athens.

Laroche, M. Kim, Ch. Tomic, M. Belisle, D. (2005). Similarities in Italian and Greek Multidimensional Ethnic Identity some Implications for Food Consumption. Canadian Journal of Administrative Sciences, 22:143-167.

Lianos, T. Sarris, A. and Katseli, L. (1996). Illegal Immigration and Local Labours Markets: the Case of Northern Greece, International Migration, 34:449-85.

Liebkind, K. (1992). Ethnic Identity Challenging the Boundaries of Social Psychology, in Breakwell, G. (Ed.), Social Psychology of Identity and the Self-Concept (14785). London, Academy.

Lyberaki, A. and Pelagidis, T. (2000). The Fear of the Foreigner in the Labour Market: Tolerances and Prejudices in Development. Athens: Polis.

Manning, A. and Roy, S. (2010). Culture Clash or Culture Club? The Identity and Attitudes of Immigrants in Britain. The Economic Journal, 120:72-100. 
Mason, P. L. (2004). Annual Income, Hourly Wages, and Identity among MexicanAmericans and Other Latinos. Industrial Relations, 43:817-834.

Nekby, L. and Rodin, M. (2010). Acculturation Identity and Employment Among Second and Middle Generation Immigrants. Journal of Economic Psychology, $31: 35-50$.

Nguyen, H. H. von Eye, A. (2002). Validating an Acculturation Scale for Vietnamese Adolescents (ASVA) a Bidimensional Perspective. International Journal for Behavioral Development, 26: 202-213.

Ott, S.(1989). The Organizational Culture Perspective. Chicago: The Dorsey Press.

Pendakur, K. and Pendakur, R. (2005). Ethnic Identity and the Labour Market. Unpublished Manuscript, Simon Fraser University, Canada.

Phillips, T. (2005). After 7/7: Sleepwalking to Segregation. Speech Given by Trevor Phillips at the Manchester Council for Community Relations, 22 September 2005.

Phinney, J. (1992). The Multi-group Ethnic Identity Measure: A New Scale for Use with Diverse Groups. Journal of Adolescent Research, 7:156-176.

Phinney, J. Horenczyk, G. Liebkind, K. and Vedder, P. (2001). Ethnic Identity, Immigration, and Well-Being. An International Perspective. Journal of Social Issues, 57:493-510.

Redfield, R. Linton, R. and Herskovits, M. J (1936). Memorandum for the Study of Acculturation. American Anthropologist, 38:149-152.

Sayegh, L. and Lasry, J. (1993). Acculturation, Stress and Mental Health Among Lebanese Immigrants in Montreal. Sante Mentale Au Quebec, 18:23-52.

Selod, H. and Zenou, Y. (2006). City-Structure, Job Search, and Labour Discrimination. Theory and Policy Implication. The Economic Journal, 116:1057-1087. 
Sen, A. (2006). Identity and Violence: The Illusion of Destiny. Allen Lane, London.

Schwartz, S. J. and Zamboanga, B. L. (2008). Testing Berry’s Model of Acculturation: A Confirmatory Latent Class Approach. Cultural Diversity and Ethnic Minority Psychology, 14:275-285.

Tajfel, H. and John, T. (1979). An Integrative Theory of Intergroup Conflict, in Worchel, S. and Austin, W. (Eds.), The Social Psychology of Intergroup Relations (33-47), Brooks/Cole, California.

Tajfel, H. (1981). Human Groups and Social Categories: Studies in Social Psychology. Cambridge University Press, Cambridge.

Turner, J. C. (1982). Towards a Cognitive Redefinition of the Social Group. In: Tajfel, H. (Ed.), Social Identity and Intergroup Relations (pp. 15-44). Cambridge University Press, Cambridge.

Unger, J. Gallaher, P. Shakib, S. Ritt-Olson, A. Palmer, P. Johnson, C. (2002). The AHISMA Acculturation Scale a New Measure of Acculturation for Adolescents in a Multicultural Society. Journal of Early Adolescence, 23:225-251. 
Table 1. Measuring immigrants' ethnic identity

\footnotetext{
A. Which one of the following four best describes your language usage:

[1] A strong identification with the Greek language coupled with a weak identification to the language of your country of origin

[2] Combination of strong identification with the Greek language and strong identification with the language of your country of origin

[3] An exclusive commitment to your original language paired with weak involvement with Greek language

[4] A weak dedication to or strong detachment from either Greek or your original language
}

B. Which one of the following four best describes your cultural habits:

[1] A strong identification with the Greek food, media, music and reading coupled with a weak identification to the food, media, music and reading of your country of origin

[2] Combination of strong identification with the Greek food, media, music and reading and strong identification with the food, media, music and reading of your country of origin

[3] An exclusive commitment to the food, media, music and reading associated with your country of origin paired with weak involvement with Greek food, media, music and reading

[4] A weak dedication to or strong detachment from either Greek or the food, media, music and reading of your country of origin

C. Which one of the following four best describes your ethnic identification:

[1] A strong identification with the Greek identification coupled with a weak identification with your country of origin identification

[2] Combination of strong identification with the Greek identification, and strong identification with your country of origin identification

[3] An exclusive commitment to your country of origin identification, paired with weak involvement with Greek identification

[4] A weak dedication to or strong detachment from either Greek or your country of origin identification

D. Which one of the following four best describes your ethnic networks:

[1] A strong close-friendship with Greeks coupled with a weak close-friendship with people of your country of origin

[2] Combination of strong close-friendship with Greeks, and strong identification with close-friendship with people of your country of origin

[3] An exclusive commitment to your country of origin close-friendship, paired with weak involvement with Greeks as close-friends

[4] A weak dedication to or strong detachment from either Greek or your country of origin close-friendship

E. Which one of the following four best describes your future citizenship plans:

[1] A strong identification with Greek citizenship and residency plans with a weak identification to citizenship and residency plans of your country of origin

[2] Combination of both Greek citizenship and residency plans, and strong identification with citizenship and residency plans of your country of origin

[3] An exclusive commitment to your country of origin citizenship and residency plans, paired with weak involvement with Greek citizenship and residency plans

[4] A weak dedication to or strong detachment from either Greek or citizenship and residency plans of your country of origin

Note. Option [1] corresponds to assimilation, option [2] corresponds to integration, option [3] corresponds to separation, and option [4] corresponds to marginalisation. Question B, which measures immigrants' cultural habits, is the average of four elements: food, media, music and reading preferences. In the real ethnic identity scale questionnaires, respondents had to response separately for each cultural habit. 
Table 2. Definitions of variables

\begin{tabular}{|c|c|}
\hline $\begin{array}{l}\text { Variable } \\
\text { Name }\end{array}$ & Definition \\
\hline $\begin{array}{l}\text { Name } \\
\text { AS }\end{array}$ & Assimilation index \\
\hline IN & Integration index \\
\hline SE & Separation index \\
\hline MA & Marginalization index \\
\hline LF & The number of labor force \\
\hline EM & The number of employed individuals \\
\hline UN & The number of unemployed individuals \\
\hline NP & The number of non-participant in the labor force (non-employed) \\
\hline ALB & 1 if individual is from Albania; 0 otherwise \\
\hline BUL & 1 if individual is from Bulgaria; 0 otherwise \\
\hline GEO & 1 if individual is from Georgia; 0 otherwise \\
\hline ROM & 1 if individual is from Romania; 0 otherwise \\
\hline RUS & 1 if individual is from Russia; 0 otherwise \\
\hline AGE & Years of age \\
\hline SEX & 1 if individual is male; 0 otherwise \\
\hline MARR & 1 if individual is married; 0 otherwise \\
\hline CHIL & Number of children in household \\
\hline MIG & Years since immigration in Greece \\
\hline CHR & 1 if the individual is Christian; 0 otherwise \\
\hline DIS & $\begin{array}{l}1 \text { if individual is limited in kind or amount of work, has a mobility limitation, or has a personal care } \\
\text { limitation; } 0 \text { otherwise }\end{array}$ \\
\hline HAR & 1 if the individual was racially harassed in Greece; 0 otherwise \\
\hline SCHOL & 1 if individual has completed minimum mandatory education; 0 otherwise \\
\hline GRAD & 1 if individual has graduated from a high school; 0 otherwise \\
\hline UNIV & 1 if individual has university or a technical school diploma; 0 otherwise \\
\hline SCHOLH & 1 if individual has completed minimum mandatory education in her/his home country; 0 otherwise \\
\hline GRADH & 1 if individual has graduated from a high school from her/his home country; 0 otherwise \\
\hline UNIVH & 1 if individual has university or a technical school diploma from her/his home country; 0 otherwise \\
\hline $\mathrm{PC}$ & 1 if individual has computer skills; 0 otherwise \\
\hline ENGL & 1 if individual has knowledge of English; 0 otherwise \\
\hline EXPER & Years of actual working experience \\
\hline EXPERH & Years of actual working experience from individual's home country \\
\hline EXPERG & Years of actual working experience from Greece \\
\hline $\mathrm{LC}$ & City controls \\
\hline
\end{tabular}


Table 3. Descriptive statistics

\begin{tabular}{|c|c|c|}
\hline & Mean & $\begin{array}{l}\text { Standard } \\
\text { Deviation }\end{array}$ \\
\hline Number of observations (employed + unemployed + non participants) & 1,837 & \\
\hline Percentage of labor force (employed + unemployed) & $77.53 \%$ & 0.41 \\
\hline Percentage of employed individuals (labor force-unemployed) & $85.30 \%$ & 0.35 \\
\hline Percentage of Albanians & $36.15 \%$ & 0.48 \\
\hline Percentage of Bulgarians & $12.51 \%$ & 0.33 \\
\hline Percentage of Georgians & $12.24 \%$ & 0.32 \\
\hline Percentage of Romanians & $18.65 \%$ & 0.38 \\
\hline Percentage of Russians & $20.45 \%$ & 0.40 \\
\hline Mean value of assimilation index & 1.10 & 1.04 \\
\hline Mean value of integration index & 1.45 & 0.54 \\
\hline Mean value of separation index & 1.90 & 0.91 \\
\hline Mean value of marginalization index & 0.54 & 0.55 \\
\hline Mean age & 36.95 & 6.02 \\
\hline Percentage of males & $37.29 \%$ & 0.48 \\
\hline Percentage who are married & $52.23 \%$ & 0.49 \\
\hline Mean number of children in household & 0.56 & 0.89 \\
\hline Mean number of immigration years in Greece & 15.43 & 4.74 \\
\hline Percentage of Christians & $62.05 \%$ & 0.48 \\
\hline Percentage with disability limitations & $10.68 \%$ & 0.30 \\
\hline Percentage of racial harassment & $86.15 \%$ & 0.58 \\
\hline Percentage completing minimum mandatory education & $75.79 \%$ & 0.42 \\
\hline Percentage of high school graduates & $64.55 \%$ & 0.47 \\
\hline Percentage of university or technical school graduates & $17.21 \%$ & 0.37 \\
\hline Percentage completing minimum mandatory education in home country & $96.76 \%$ & 0.17 \\
\hline Percentage of high school graduates in home country & $92.48 \%$ & 0.26 \\
\hline Percentage of university or technical school graduates in home country & $77.07 \%$ & 0.42 \\
\hline Percentage with computing skills & $19.73 \%$ & 0.39 \\
\hline Percentage with English skills & $25.24 \%$ & 0.43 \\
\hline Mean years of actual working experience & $18.08 \%$ & 5.70 \\
\hline Mean years of actual working experience in Greece & $14.4 \%$ & 4.29 \\
\hline Percentage living in the capital of Greece (Athens) & $38.13 \%$ & 0.29 \\
\hline
\end{tabular}
Notes: Data Source, Greek Migration Study (2009-2010). 
Table 4. Coefficients from estimations of the formation of identity

\begin{tabular}{|c|c|c|c|c|}
\hline & Assimilation & Integration & Separation & Marginalization \\
\hline Labor force & $0.121(0.056)^{*}$ & $0.055(0.029)^{* *}$ & $-0.061(0.028)^{*}$ & $-0.038(0.019)^{*}$ \\
\hline Employed & $0.150(0.068)^{*}$ & $0.128(0.105)$ & $-0.054(0.023)^{*}$ & $0.123(0.079)$ \\
\hline Bulgarians & $0.196(0.172)$ & $0.154(0.089)$ & $0.219(0.103)^{*}$ & $0.067(0.059)$ \\
\hline Georgians & $-0.104(0.073)$ & $-0.120(0.062)^{* *}$ & $0.073(0.039) * * *$ & $0.236(0.170)$ \\
\hline Romanians & $0.197(0.105)$ & $-0.204(0.093)^{*}$ & $0.213(0.176)$ & $0.254(0.106)^{*}$ \\
\hline Russians & $0.164(0.153)$ & $0.119(0.061)^{* * *}$ & $-0.276(0.109)^{*}$ & $-0.193(0.127)$ \\
\hline Age & $-0.038(0.009)^{*}$ & $-0.026(0.010)^{*}$ & $0.056(0.038)$ & $0.081(0.0144)$ \\
\hline $\mathrm{Age}^{2}$ & $0.001(0.002)$ & $0.001(0.002)$ & $-0.002(0.003)$ & $-0.001(0.002)$ \\
\hline Men & $0.031(0.018)^{* * * *}$ & $0.058(0.046)$ & $0.083(0.143)$ & $0.146(0.098)$ \\
\hline Married & $0.215(0.206)$ & $0.201(0.171)$ & $-0.173(0.111)$ & $-0.196(0.184)$ \\
\hline Number of children & $-0.106(0.092)$ & $0.314(0.247)$ & $-0.241(0.194)$ & $-0.225(0.243)$ \\
\hline $\begin{array}{l}\text { Years of immigration in } \\
\text { Greece }\end{array}$ & $0.024(0.003)^{*}$ & $0.016(0.004)^{*}$ & $0.005(0.007)$ & $0.003(0.016)$ \\
\hline Christians & $-0.081(0.137)$ & $0.173(0.089)^{* *}$ & $-0.095(0.113)$ & $-0.219(0.111)^{* * *}$ \\
\hline Disability status & $-0.052(0.031)$ & $0.027(0.023)$ & $0.016(0.009) * * *$ & $0.103(0.079)$ \\
\hline $\begin{array}{l}\text { Minimum } \\
\text { education }\end{array}$ & $-0.134(0.082)$ & $-0.115(0.061)^{* * * *}$ & $-0.158(0.132)$ & $0.342(0.218)$ \\
\hline $\begin{array}{l}\text { University or technical } \\
\text { school diploma }\end{array}$ & $0.217(0.102)^{*}$ & $0.169(0.039)^{*}$ & $-0.041(0.013)^{*}$ & $-0.079(0.068)$ \\
\hline $\begin{array}{l}\text { Minimum mandatory } \\
\text { education in home country }\end{array}$ & $0.152(0.116)$ & $-0.206(0.049)^{*}$ & $-0.027(0.021)$ & $-0.116(0.134)$ \\
\hline $\begin{array}{l}\text { University or technical } \\
\text { school diploma in home } \\
\text { country }\end{array}$ & $0.226(0.108)^{*}$ & $0.199(0.072)^{*}$ & $-0.064(0.022)^{*}$ & $-0.116(0.095)$ \\
\hline Knowledge of computer & $0.081(0.072)$ & $0.077(0.054)$ & $-0.212(0.203)$ & $-0.118(0.126)$ \\
\hline Knowledge of English & $0.209(0.058)^{*}$ & $0.372(0.126)^{*}$ & $0.151(0.113)$ & $-0.309(0.215)$ \\
\hline City controls & yes & yes & yes & yes \\
\hline Pseudo $\mathrm{R}^{2}$ & 0.104 & 0.085 & 0.076 & 0.139 \\
\hline Observations & 1,981 & 1,981 & 1,981 & 1,981 \\
\hline
\end{tabular}

Notes: Data Source, Greek Migration Study (2009-2010). Each column is a separate regression. Standard errors are in parenthesis. *Significant at the 1\% level. ** Significant at the 5\% level. *** Significant at the $10 \%$ level. 
Table 5. Coefficients from employment regression, marginal effects

\begin{tabular}{ll}
\hline Assimilation & $0.069(0.007)^{*}$ \\
Integration & $0.051(0.004)^{*}$ \\
Separation & $-0.126(0.005)^{*}$ \\
Marginalization & $-0.142(0.005)^{*}$ \\
Bulgarians & $-0.076(0.007)^{*}$ \\
Georgians & $-0.130(0.012)^{*}$ \\
Romanians & $-0.082(0.024)^{*}$ \\
Russians & $0.076(0.041)^{* * *}$ \\
Age & $0.053(0.015)^{*}$ \\
Age & $-0.0004(0.0001)^{*}$ \\
Men & $0.187(0.017)^{*}$ \\
Married & $0.121(0.018)^{*}$ \\
Number of children & $0.073(0.011)^{*}$ \\
Years of immigration in Greece & $0.094(0.004)^{*}$ \\
Christians & $0.018(0.024)$ \\
Disability status & $-0.205(0.006)^{*}$ \\
Minimum mandatory education & $0.160(0.042)^{*}$ \\
University or technical school diploma & $0.322(0.010)^{*}$ \\
Minimum mandatory education in home country & $0.094(0.050)^{* * *}$ \\
University or technical school diploma in home country & $0.234(0.027)^{*}$ \\
Knowledge of computer & $0.038(0.021)^{* *}$ \\
Knowledge of English & $0.067(0.005)^{*}$ \\
Actual work experience in home country & $0.129(0.006)^{*}$ \\
Actual work experience in Greece & $0.168(0.006)^{*}$ \\
City controls & yes \\
Pseudo R & 0.261 \\
Observations & 1,422 \\
\hline
\end{tabular}

Notes: Data Source, Greek Migration Study (2009-2010). Standard errors are in parenthesis. *Significant at the $1 \%$ level. $* *$ Significant at the $5 \%$ level. $* * *$ Significant at the $10 \%$ level. 
Table 6. Coefficients from employment regression per ethnic group, marginal effects

\begin{tabular}{|c|c|c|c|c|c|}
\hline & Albanians & Bulgarians & Georgians & Romanians & Russians \\
\hline Assimilation & $0.061(0.012)^{*}$ & $0.073(0.005)^{*}$ & $0.078(0.004)^{*}$ & $0.068(0.009)^{*}$ & $0.060(0.007)^{*}$ \\
\hline Integration & $0.057(0.004) *$ & $0.059(0.008)^{*}$ & $0.062(0.003)^{*}$ & $0.058(0.004)^{*}$ & $0.048(0.006)^{*}$ \\
\hline Separation & $-0.138(0.006)^{*}$ & $-0.158(0.011)^{*}$ & $-0.162(0.002)^{*}$ & $-0.139(0.005)^{*}$ & $-0.132(0.004)^{*}$ \\
\hline Marginalization & $-0.140(0.002)^{*}$ & $-0.160(0.002)^{*}$ & $-0.173(0.002)^{*}$ & $-0.146(0.004)^{*}$ & $-0.148(0.003)^{*}$ \\
\hline Age & $0.054(0.016) *$ & $0.058(0.013)^{*}$ & $0.057(0.012)^{*}$ & $0.054(0.014)^{*}$ & $0.057(0.015)^{*}$ \\
\hline $\mathrm{Age}^{2}$ & $-0.0004(0.000)^{*}$ & $-0.0004(0.000)^{*}$ & $-0.0003(0.000)^{*}$ & $-0.0003(0.000)^{*}$ & $-0.0004(0.0001)^{*}$ \\
\hline Men & $0.186(0.016)^{*}$ & $0.175(0.008)^{*}$ & $0.169(0.013)^{*}$ & $0.194(0.015)^{*}$ & $0.171(0.015)^{*}$ \\
\hline Married & $0.118(0.016) *$ & $0.119(0.017)^{*}$ & $0.125(0.029)^{*}$ & $0.128(0.012)^{*}$ & $0.132(0.014)^{*}$ \\
\hline Number of children & $0.072(0.010)^{*}$ & $0.077(0.005)^{*}$ & $0.085(0.007)^{*}$ & $0.072(0.009)^{*}$ & $0.074(0.004)^{*}$ \\
\hline $\begin{array}{l}\text { Years of immigration } \\
\text { in Greece }\end{array}$ & $0.091(0.004)^{*}$ & $0.103(0.006)^{*}$ & $0.119(0.004)^{*}$ & $0.089(0.002)^{*}$ & $0.092(0.003)^{*}$ \\
\hline Christians & $0.006(0.008)$ & $0.031(0.021)$ & $0.026(0.018)$ & $0.016(0.025)$ & $0.017(0.012)$ \\
\hline Disability status & $-0.229(0.005)^{*}$ & $-0.238(0.010)^{*}$ & $-0.194(0.004)^{*}$ & $-0.241(0.009)^{*}$ & $-0.254(0.014) *$ \\
\hline $\begin{array}{l}\text { Minimum mandatory } \\
\text { education }\end{array}$ & $0.157(0.049)^{*}$ & $0.167(0.037)^{*}$ & $0.143(0.024)^{*}$ & $0.130(0.019)^{*}$ & $0.166(0.029)^{*}$ \\
\hline $\begin{array}{l}\text { University or } \\
\text { technical school } \\
\text { diploma }\end{array}$ & $0.331(0.007)^{*}$ & $0.341(0.014)^{*}$ & $0.210(0.006)^{*}$ & $0.249(0.005)^{*}$ & $0.263(0.040)^{*}$ \\
\hline $\begin{array}{l}\text { Minimum mandatory } \\
\text { education in home } \\
\text { country }\end{array}$ & $0.112(0.062)^{* *}$ & $0.102(0.058)$ & $0.084(0.064)$ & $0.077(0.048)$ & $0.123(0.052)^{*}$ \\
\hline $\begin{array}{l}\text { University or } \\
\text { technical school } \\
\text { diploma in home } \\
\text { country }\end{array}$ & $0.250(0.007)^{*}$ & $0.178(0.070)^{*}$ & $0.166(0.012)^{*}$ & $0.149(0.023)^{*}$ & $0.277(0.023)^{*}$ \\
\hline $\begin{array}{l}\text { Knowledge of } \\
\text { computer }\end{array}$ & $0.045(0.011)^{*}$ & $0.031(0.026)$ & $0.022(0.019)$ & $0.034(0.024)$ & $0.035(0.015)^{*}$ \\
\hline $\begin{array}{l}\text { Knowledge of } \\
\text { English }\end{array}$ & $0.086(0.005)^{*}$ & $0.042(0.032)$ & $0.055(0.040)$ & $0.053(0.020)^{*}$ & $0.101(0.032)^{*}$ \\
\hline $\begin{array}{l}\text { Actual work } \\
\text { experience } \\
\text { in home country }\end{array}$ & $0.134(0.004)^{*}$ & $0.126(0.003)^{*}$ & $0.111(0.005)^{*}$ & $0.128(0.004)^{*}$ & $0.142(0.004)^{*}$ \\
\hline $\begin{array}{l}\text { Actual work } \\
\text { experience in Greece }\end{array}$ & $0.154(0.004)^{*}$ & $0.136(0.003)^{*}$ & $0.134(0.002)^{*}$ & $0.143(0.003)^{*}$ & $0.166(0.003)^{*}$ \\
\hline City controls & yes & yes & yes & yes & yes \\
\hline Pseudo $\mathrm{R}^{2}$ & 0.238 & 0.343 & 0.267 & 0.305 & 0.282 \\
\hline Observations & 490 & 172 & 164 & 274 & 322 \\
\hline
\end{tabular}

Notes: Data Source, Greek Migration Study (2009-2010). Each column is a separate regression. Standard errors are in parenthesis. *Significant at the 1\% level. ** Significant at the 5\% level. *** Significant at the 10\% level. 
Table 7. Variations in employment rates per ethnic group and ethnic identity

\begin{tabular}{lllllll}
\hline & Total & Albanians & Bulgarians & Georgians & Romanians & Russians \\
& & & & & & \\
Assimilation & 0.169 & 0.151 & 0.182 & 0.211 & 0.165 & 0.147 \\
Integration & 0.082 & 0.097 & 0.089 & 0.188 & 0.113 & 0.102 \\
Separation & -0.119 & -0.092 & -0.104 & -0.160 & -0.108 & -0.137 \\
Marginalization & -0.235 & -0.211 & -0.242 & -0.231 & -0.238 & -0.208 \\
\hline
\end{tabular}

Notes: Data Source, Greek Migration Study (2009-2010).Each column is a separate calculation. 